\title{
The salmon-peloton: hydraulic habitat shifts of adult Atlantic salmon (Salmo salar) due to behaviour thermoregulation
}

4 Running title: The salmon-peloton: thermo-hydraulic habitats of adult Atlantic salmon

5

6 Antóin M. O’Sullivan ${ }^{1,2 *}$, Tommi Linnansaari ${ }^{1,2,3}$, Jaime Leavitt ${ }^{1,4}$, Kurt M. Samways ${ }^{1,5}$, Barret

$10{ }^{1}$ Canadian Rivers Institute

$11{ }^{2}$ FOREM, University of New Brunswick (Fredericton)

$12{ }^{3}$ Biology, University of New Brunswick (Fredericton)

$13{ }^{4}$ Civil Engineering, University of New Brunswick (Fredericton)

$14{ }^{5}$ Biological Sciences, University of New Brunswick (Saint John)

$15{ }^{6}$ Civil and Resource Engineering, Dalhousie University (Halifax)

17 *corresponding author: Antóin M. O’Sullivan (aosulliv@unb.ca)

\section{Acknowledgements}

20 First, the authors would like to thank Lord Pisces. The authors wish to thank the Collaboration for

21 Atlantic Salmon, J.D. Irving, Limited, Cooke Aquaculture, NSERC (RGPIN-2018-06015 - RAC)

22 and New Brunswick's Wildlife Trust Fund. The work also received partial financial contributions

23 from the Fisheries and Oceans Canada / Ce Project fut partiellement appuyé par une contribution

24 financière de Pêches et Océans Canada, The Atlantic Salmon Conservation Foundation, Mirmaichi

25 Salmon Association, and New Brunswick's Innovation Foundation. We thank K. Haralampides, 26 and D. Connor for assistance collecting ADCP data. We also thank an unnamed fishing club on 27 the Southwest Miramichi for site access. 


\section{Conflict of Interest Statement}

29 The author's declare no conflict of interest.

\section{Abstract}

32 In recent decades there has been an increase in conservation and restoration projects targeting 33 Atlantic salmon (Salmo salar - AS), as populations in eastern Canada decline. Missing however,

34 is an understanding of thermo-hydraulic habitat use by adult AS during summer, and thus the 35 actual benefits of altering in-river physical structures. Here, we illustrated how optical and thermal 36 infrared (TIR) imagery acquired from a UAV can be used in concert with in-situ depth and velocity 37 data to map adult AS and develop models of thermo-hydraulic habitats in the Miramichi River, 38 New Brunswick. We found during optimal thermal conditions $\left(<19{ }^{\circ} \mathrm{C}\right)$ proximity to boulders and Froude numbers, a non-dimensional hydraulic metric, were key parameters that characterized adult AS habitat. However, during behavioural thermoregulation events $\left(>19{ }^{\circ} \mathrm{C}\right)$, proximity to

41 the cool thermal plume and Froude number, a non-dimensional hydraulic parameter, were critical

42 controls on habitat use. We also observed AS formed a distinct geometric formation during 43 behavioural thermoregulation events, and term this formation a 'thermal-peloton'. The primary 44 function of the peloton is undoubtedly to reduce thermally induced stressed; however, we 45 conceptualize the geometry of the peloton attenuates hydraulic-drag, and reduces energetic expenditure of individuals practicing behavioural thermoregulation. These data provide an unrivaled viewpoint of thermo-hydraulic habitat selection by adult AS, and a blue print for restoration work. The use of UAV-based sensors has the potential to instigate a paradigm shift

49 for river sciences. The age of applying hyper-resolution, remote sensing for river science and aquatic ecology is immensely exciting.

52 Keywords: Atlantic salmon; behavioural thermoregulation; optical bathymetry; Random Forest, 53 thermal infrared; UAV 


\section{Introduction}

58 Atlantic salmon (Salmo salar) are a charismatic fish species native to many rivers in eastern North

59 America, Northern and Western Europe, and Russia (Webb et al., 2007), and support multi-billion

60 dollar fisheries. The physical attributes that determine suitable Atlantic salmon (AS) habitat, such

61 as spawning habitat, have been linked to depth and velocity (Malcom et al., 2008). Moir et al.

62 (2002) found Froude numbers, a non-dimensional hydraulic parameter based on the relationship

63 between depth, velocity, and gravity, were strong predictors of spawning habitats. These hydraulic

64 conditions are thought to remove fine clasts during redd construction and to help oxygenate eggs

65 (Gillies and Moir, 2015). A plethora of studies have revealed the hydraulic regimes that

66 characterize juvenile habitats during both summer and winter (e.g. Heggenes et al., 1990;

67 Linnansaari and Cunjak, 2013). Heggenes, (1996) proposed that juvenile habitat selection is a

68 function of potential net energy gains related to the velocity regime: access to drifting food

69 availability define gains while swimming energy expenditure define costs. For adult AS returning

70 to, and migrating up, rivers deep pools are suggested to be critical habitats (Crisp, 1996), while

71 boulders have been linked to protection for predation (e.g., Keenleyside, 1962; Gibson, 1993).

While river hydraulics exert critical control on aquatic habitats, temperature is an equally,

73 if not more, important determinate of suitable habitat (Breau et al., 2007) particularly for salmonids

74 and other cold-water ectotherms (e.g., Morash et al., 2020). During summer, if water temperatures

75 exceed critical thermal thresholds, AS can reduce metabolic and individual physiologic stress

76 through 'behavioural thermoregulation' (Reynolds et al., 1979). This behaviour leads AS to

77 seeking thermal refuge in cooler areas; cooler areas that are often sourced from shaded tributaries

78 (Ebersole et al., 2003), groundwater-dominated tributaries (Corey et al., 2020), and springs

79 (Torgersen et al., 1999). Thermal refuges may have unique hydraulic characteristics in addition

80 to being thermally distinct (Ritter et al., 2020). For instance, Wilbur et al. (2020) found large sea-

81 run brook trout (Salvelinus fontinalis) sought thermal refuges that were cold, but also deep.

Advancements in remote sensing has led to an exponential growth in the capacity to

83 quantify physical features within fluvial environments (Torgersen et al., 1999; Legleiter and

84 Harrison, 2019). Techniques for mapping river bathymetry include active methods, such as

85 topobathymetric LiDAR mapping, and passive methods, such as optically derived bathymetric

86 mapping (Marcus and Fonstad, 2010). While these mapping techniques first occurred in the

87 geomorphic realm, they are beginning to be applied in ecohydraulic studies from reach (Lane et 
al., 2020) to catchment scales (O'Sullivan et al., 2020). As mapping techniques have evolved, concurrent advances in unmanned aerial vehicle (UAV) technology enable the mapping of Earth structures at unprecedented spatial and temporal scales. In the context of this study, recent research has illustrated the utility of bathymetric stream mapping by combing UAV obtained data and structure-form-motion techniques (Lane et al., 2020), as well as longitudinal stream temperature mapping using UAV-mounted thermal infrared (TIR) sensors (Casas-Mulet et al., 2020).

In recent decades there has been an increase in conservation and restoration projects targeting AS as populations in eastern Canada decline. These projects are often multifaceted including the restoration of not just hydraulic habitats (Lacey and Miller, 2004), but also thermal habitats (Justice et al., 2017). River hydraulic characteristics define adult AS habitat, and in summer, as river temperatures increase, temperature will affect habitat availability and selection where AS select for thermal refuge to offset physiological stress (Frechette et al., 2018; Lennox et al., 2018). The occurrence of thermal refuges is a function of landscape characteristics and riverscape hydraulics (O'Sullivan et al., 2020; Ritter et al., 2020), and it appears both adult and juvenile AS can locate them (Frechette et al., 2018; Corey et al., 2020). These refuges are often

104 known within local communities and by river managers who act to protect AS during predicted 105 behavioural thermoregulation events (e.g., DFO, 2012). More recently, managers have noted that 106 thermal habitats in summer may be augmented (Kurylyk et al., 2015; Ouellette et al., 2020) and 107 have begun to alter instream habitats to create "cold water pools" for example (N. Wilbur, Regional 108 Director Atlantic Salmon Federation, pers. comm.). Missing however is an understanding of 109 thermo-hydraulic habitat use by adult AS during summer, and winter, and thus the actual benefits 110 of altering in-river physical structures, e.g., the created hydraulic conditions, temporal persistent 111 of created structure, and implications for the non-adult AS components of the ecosystem.

We use remote sensing techniques to passively quantify hydraulic preferences for adult AS 114 before and during a thermal aggregation event on the Miramichi River, New Brunswick. We use 115 TIR and red-green-blue (RGB) sensors mounted to an airborne UAV as well as in-situ depth and 116 velocity data collected from an acoustic Doppler current profiler (ADCP) and RTK dGPS 117 processed using a RF model approach. The AS behaviour was inferred from RGB data (e.g., 
118 Andrews at al. 2020) to develop movement patterns and habitat preference indices for each thermal

119 condition (e.g., Mocq et al 2018; Wilbur et al., 2020). Our goal is to demonstrate the hydraulic

120 conditions of preferred habitats for adult AS during a summer, behavioural thermoregulation

121 event. In doing so, we hope to provide guidance for protecting and where necessary, creating adult

122 AS habitat during the extreme temperatures of summer.

\section{$123 \quad 2$ Methods}

\section{$124 \quad 2.1 \quad$ Study area}

125 The study area is a 2.2 ha reach that includes the confluence of an unnamed tributary and the main

126 stem of the Southwest Miramichi River, a northern temperate catchment in New Brunswick,

127 Canada (Figure. 1). The Southwest Miramichi drains 7,700 km, and during summer is

128 hydrologically characterised by low flows and warm temperatures (Caissie et al., 2007). Average

129 August discharge from 1961-2018 $=74.9 \mathrm{~m}^{3} \cdot \mathrm{s}^{-1}$, with average minimum discharge values for the

130 same period $=19.5 \mathrm{~m}^{3} \cdot \mathrm{s}^{-1}$ (Environment and Climate Change Canada (ECCC) gauge station:

131 01BO001). In the year of this study (August and early September 2020), the river experienced

132 extreme low flows with an August minimum discharge $=8.6 \mathrm{~m}^{3} \cdot \mathrm{s}^{-1}$, the lowest August discharge

133 since 1961. The long-term average maximum, average mean and average minimum air

134 temperatures in August $=24.4^{\circ} \mathrm{C}, 12.3^{\circ} \mathrm{C}$, and $18.4{ }^{\circ} \mathrm{C}$, respectively (from 1943-2019; ECCC:

135 8100989). During these low flow, high air temperature situations, river water temperatures can

136 exceed $30{ }^{\circ} \mathrm{C}$ (Breau et al., 2011; Corey et al., 2020). The 2 ha study site is located adjacent to a

137 coldwater tributary that generates a coldwater plume in the main river, and adjacent to a private

138 fishing club. 

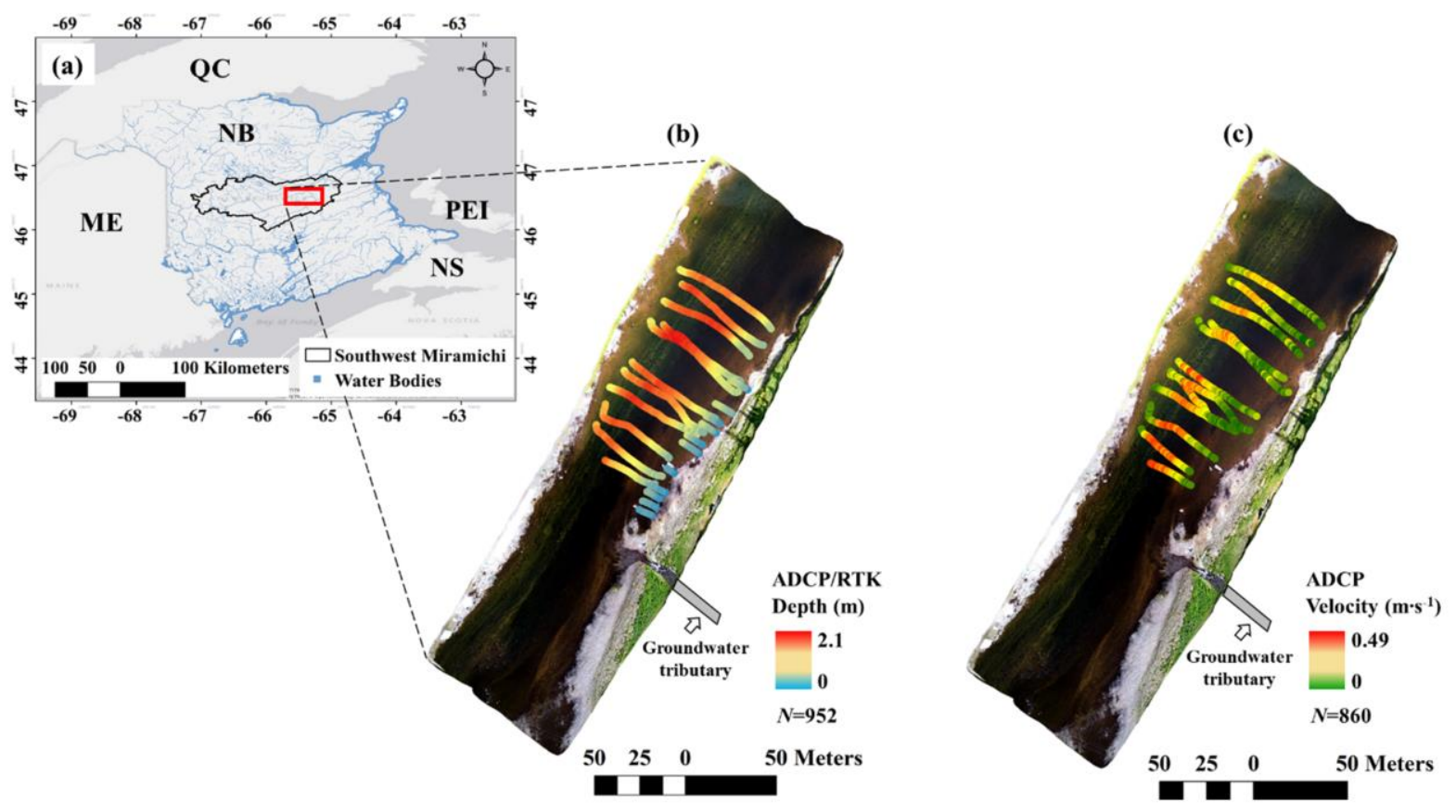

141 Figure 1 The geographic location of our study area located on the Southwest Miramichi, a 142 tributary of the Miramichi River, New Brunswick (NB) denoted by the red polygon (a). Depth 143 data were acquired via ADCP and RTK dGPS (b) and velocity data were collected via ADCP (c).

\subsection{Workflow}

146 The study approach followed four steps (Figure. 2). Step 1 involved the collection of UAV-based

147 TIR data to delimit the spatial extent of the thermal plume, RGB optical imagery to observe AS

148 aggregations and develop a suite of passive bathymetry models, and depth and velocity calibration

149 data using a remote-controlled acoustic Doppler current profiler (ADCP), and Real-Time Kinematic

150 and Differential GPS (RTK dGPS). Step 2 involved image and calibration data processing. In Step 3,

151 hydraulic models were developed for the image datasets. Finally, in Step 4, preference curves were 152 developed to investigate changes in thermo-hydraulic habitat selection before (optimal thermal 153 conditions - see below) and during behavioural thermoregulation. 


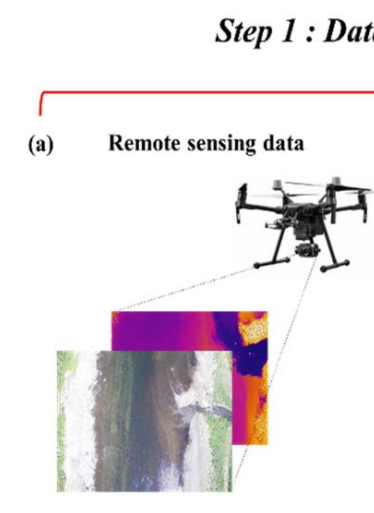

collection

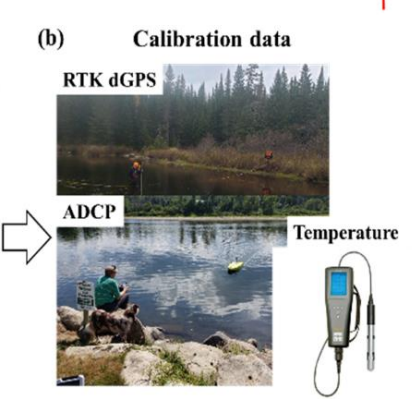

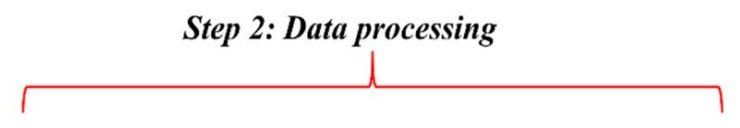

(c)

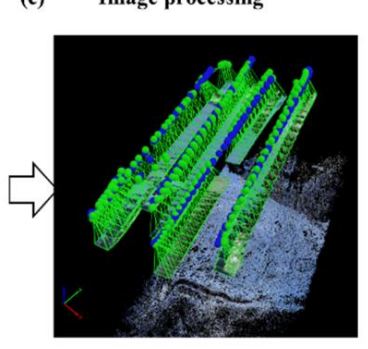

(d) Calibration data processing

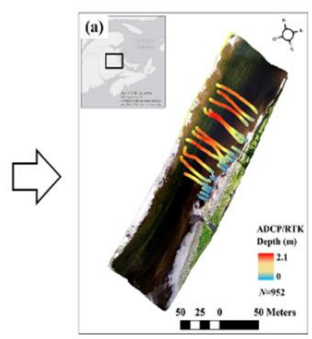

Step 3: Thermo-hydraulic model development

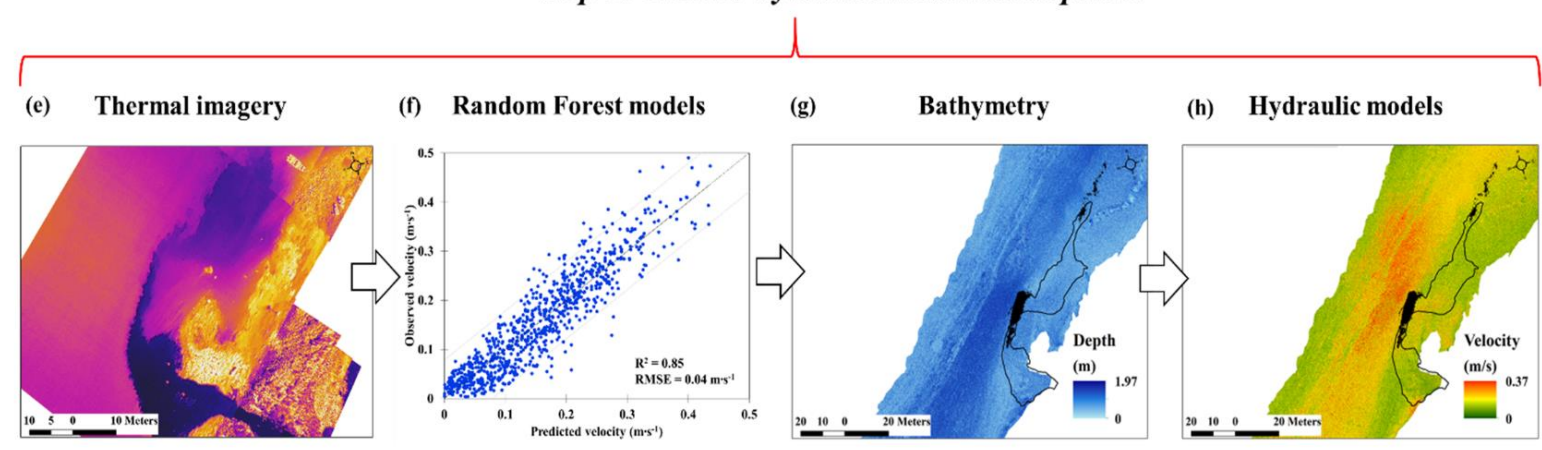

Step 4: Preference curves for optimal and behavioural thermoregulation regimes

(i)

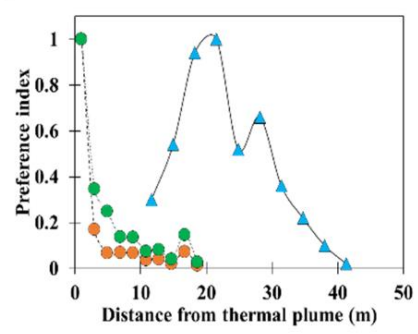

Preference curves

Figure 2 A workflow illustrating the steps to assess thermo-hydraulic conditions preferred by adult Atlanitc salmon for optimal and behavioural thermoregulation conditions.

\subsection{Data collection}

159 Adult AS often occupy well defined and pools during summer in the Southwest Miramichi (DFO,

160 2012). Our sample times were chosen when the local fishing camp guides observed behavioural

161 thermoregulation and optimal thermal events, at which time we were alerted and conducted our

162 data collection. 


\subsubsection{Remote sensing imagery and field data}

\section{Remote sensing imagery}

165 Remotely sensed imagery was collected from a DJI, Zenmuse XT2 thermal camera (19 mm) mounted to a DJI M210 RTK. The Zemmuse XT2 sensor is a dual FLIR Tau 2 thermal camera

$167(7.5-13.5 \mu \mathrm{m})$ with a 4K RGB camera. Images for the behavioural thermoregulation conditions 168 were collected at 10:30 August 24, 2020 and at 14:54 September 11, 2020. We defined 'optimal 169 thermal conditions' as instances when AS are not observed to be behaviourally thermoregulating, 170 and data for optimal thermal conditions were collected at 13:46 August 28, 2020. All days for 171 image collection were cloudless, and water temperature of the main river was 19.1, 17.7 and 20.2 $172{ }^{\circ} \mathrm{C}$ during August, 24, 28, and September 11, respectively (see Table 1). The tributary, and the 173 apparent thermal refuge in the main river, was $14.3,14.2$, and $14.2^{\circ} \mathrm{C}$ on each sampling day (Table 174 1).

175

Table 1 Sensor and flight information and hydroclimatic conditions for each mapping episode.

\begin{tabular}{lccc}
\hline Date/ Time & $8 / 24 / 2020 ; 10: 30$ & $8 / 28 / 2020 ; 13: 46$ & $9 / 11 / 2020 ; 14: 54$ \\
\hline Atlantic Salmon behaviour & $\begin{array}{c}\text { Behavioural } \\
\text { thermoregulation }\end{array}$ & $\begin{array}{c}\text { Optimal thermal } \\
\text { conditions }\end{array}$ & $\begin{array}{c}\text { Behavioural } \\
\text { thermoregulation }\end{array}$ \\
\hline Air temperature $\left({ }^{\circ} \mathrm{C}\right)$ & 25.4 & 21 & 18.1 \\
\hline Main stem temperature $\left({ }^{\circ} \mathrm{C}\right)$ & 19.1 & 17.7 & 20.2 \\
\hline Tributary temperature $\left({ }^{\circ} \mathrm{C}\right)$ & 14.3 & 14.2 & 14.2 \\
\hline $\begin{array}{l}\text { Water level }(\mathrm{m}) \\
(\text { ECCC gauge station: 01BO001) }\end{array}$ & 0.37 & 0.44 & 0.37 \\
\hline
\end{tabular}

179 from uncooled thermal sensors, such as the FLIR Tau 2, can display a relatively large amount of 180 thermal drift (see Dugdale et al., 2019), which can be corrected with calibration data from in181 stream thermographs. However, the imagery was not calibrated in this study as the primary focus 182 was to investigate changes in hydraulic preferences between optimal and behavioural 183 thermoregulation conditions, i.e., the TIR images were used to delineate the thermal plume and 184 demonstrate that AS were practicing behavioural thermoregulation. Point temperature 
185

186

187

188

189

190

191

192

193

194

195

196

197

198

199

200

201

202

203

204

205

206

207

208

209

\section{0}

211

212

213

measurements were taken for the air, main stem and tributary, using a YSI Sonde $\left( \pm 0.3^{\circ} \mathrm{C}\right.$; Table $1)$.

Both the RGB and TIR imagery were processed in Pix4DMapper @ using the '3D model' module. The image resolution was $3 \mathrm{~cm}$ for the RGB imagery and $7 \mathrm{~cm}$ for the TIR images. We resampled the RGB imagery to $5 \mathrm{~cm}$ resolution prior to development of optical derived depth models to reduce noise effects of image speckling (e.g., Jordan and Fonstad, 2005).

\section{Field data}

Depth and velocity data were synchronously collected on August 24 using an ADCP ARCboat (HR Wallingford) sampled at $3 \mathrm{MHz}$. ADCP data were filtered (depths $<0.3 \mathrm{~m}$ removed) to remove potentially erroneous measurements (Guerro and Lamberti, 2011). Shallow depth measurements were collected using an RTK dGPS on August 24. In total $N=952$ depth data points $(N=860 \mathrm{ADCP} ; N=92 \mathrm{RTK}$ GPS), and $N=860$ velocity data points were collected (Figure. 1). The average, minimum, and maximum measured depths were $1.07 \mathrm{~m}, 0.01 \mathrm{~m} 2.1 \mathrm{~m}$ $(\mathrm{SD}=0.6 \mathrm{~m})$, respectively, and the average, minimum, and maximum measured velocities were $0.15 \mathrm{~m} \cdot \mathrm{s}^{-1}, 0 \mathrm{~m} \cdot \mathrm{s}^{-1}$, and $0.49 \mathrm{~m} \cdot \mathrm{s}^{-1}$, respectively (Figure. $1 \mathrm{~S} 1$ ). Water levels, taken at the ECCC gauge station: 01BO001, were relatively stable during the study period (Table 1), and the August 24 depth and velocity data were used to calibrate image-derived hydraulic models for each day.

The extent of the August $28^{\text {th }}$ image was shorter than the August $24^{\text {th }}$ and September $11^{\text {th }}$ images. However, this was outside of the range of observed habitat use in the image, and did not affect the overall study. The reduction in image extent lead to a decrease in field calibration data points for the August $28^{\text {th }}$ image, where depth samples were reduced to $N=771$ and velocity samples were reduced to $N=744$.

\subsection{Hydraulic and thermal characteristics}

Passive optical bathymetric mapping (e.g.s Legleiter and Harrison, 2019) exploits the relationship between light attenuation in the water column and depth to produce a bathymetric map (Marcus and Fonstad, 2010). In this study, we used the high-resolution RGB imagery to construct optical 
214 bathymetric maps. The red band $(635 \mathrm{~nm})$ in our imagery was found to best characterize depth 215 variability and was chosen for the depth mapping exercise. A transform is required to capture the 216 exponential nature of light attenuation in the water column (Lyzenga, 1981):

$$
X=\ln (D N-\min (D N)+1)
$$

218 where $X$ is an image-derived quantity, $D N$ is the digital number of the band, and 1 is added to the 219 expression as the natural log can only be calculated for positive values.

220 Machine-leaning algorithms are commonly used for optical depth mapping (e.g., Sagawa 221 et al., 2020). We chose a Random Forest (RF) model and utilised the forest-based classification 222 and regression tool in ArcGIS Pro (ESRI, 2020) calibrated with field depth measurements to 223 predict depth from the $X$ image from each observation. Similar to the depth mapping modelling 224 approach, we used the forest-based classification and regression tool in ArcGIS Pro (ESRI, 2020) 225 and the field velocity measurements to build velocity models for each observation. shown strong correlations with AS spawning site selection (Moir et al., 2002). In this study we investigate the efficacy of $F r$ to explain habitat use by adult AS:

where $V$ is the velocity of each pixel determined from the velocity RF model $\left(\mathrm{m} \cdot \mathrm{s}^{-1}\right), g$ is the gravitational acceleration constant $\left(9.81 \mathrm{~m} \cdot \mathrm{s}^{-2}\right)$, and $d$ is the depth of each pixel determined from

233 the depth RF model (m). We modelled Fr using the forest based classification and regression tool 234 in ArcGIS Pro (ESRI, 2020). mitigate against uncertainty. 


\subsection{Hydraulic habitat selection}

241 Habitat preference indices

242 We manually delimited the spatial position of fish for all 3 dates in the RGB images. For optimal 243 thermal conditions (August 28) $N=233$ individuals were identified. It was not possible to 244 demarcate individual fish for the dates of the apparent behavioural thermoregulation because the 245 fish were aggregated closely together. Instead, a polygon was drawn around the aggregation for

246 both August and September apparent behavioural thermoregulation events, along with any fish 247 that could be individually identified proximal to the aggregation.

248 Following the delineation of AS, the polygons were overlain on the suite of depth, 249 velocity and Fr maps, and values were extracted. To examine the influence of boulders and the 250 thermal plume on habitat preferences, a proximity analyses was conducted in ArcMap using the 251 'near (analysis)' tool (ESRI, 2020), and the distance of fish from each feature was quantified.

253 (see Heggens, 1996). We calculated habitat preference indices by:

$$
H P I=f / f_{\max }
$$

255 where HPI is the habitat preference index, $f$ is the frequency individuals are observed to select 256 for a certain habitat type, (temperature, depth, velocity, $F r$, and distance from boulders), and $f_{\text {max }}$ 257 is the maximum observed frequency of a habitat type selected. Preference indices range from 0 258 (not selected) to 1 indicating preferred habitat.

\section{$2603 \quad$ Results}

\section{$261 \quad 3.1 \quad$ Adult Atlantic salmon behaviour}

262 The apparent behavioural thermoregulation events were observed on August 24 and September 11

263 (Figure 3a and c). The optimal (non-event) behaviour is shown for August 28 (Figure 3b), and the 264 coldwater plume in the main river on August is shown in Figure 3d. 
bioRxiv preprint doi: https://doi.org/10.1101/2021.04.19.440497; this version posted April 20, 2021. The copyright holder for this preprint (which was not certified by peer review) is the author/funder, who has granted bioRxiv a license to display the preprint in perpetuity. It is made available under aCC-BY-NC-ND 4.0 International license.
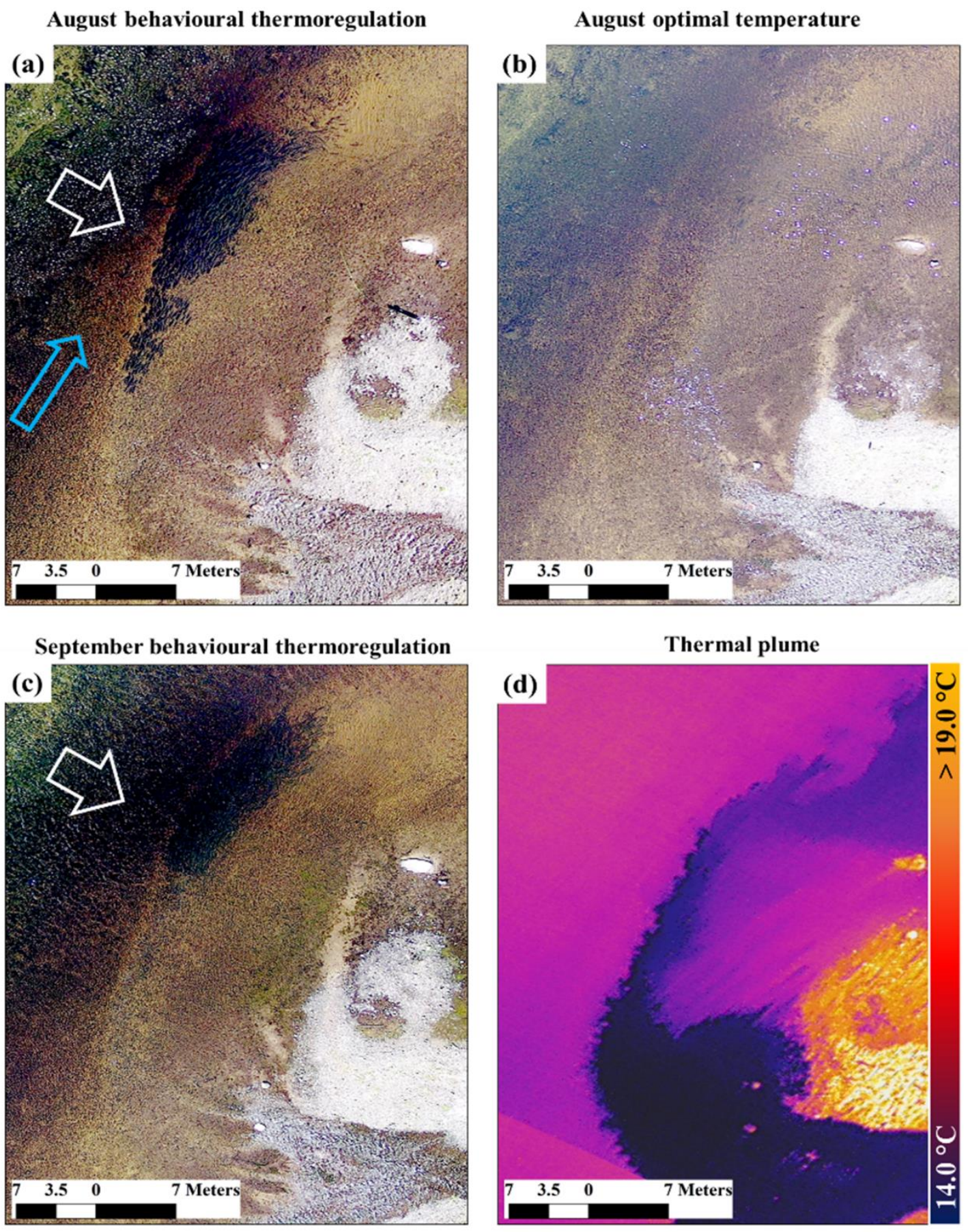

267 Figure 3 The behaviour of adult Atlantic salmon during two apparent, behavioural 268 thermoregulation events on August 24 (a) and September 11 (c). Aggregations are demarcated 269 with the white arrows, and flow direction by the blue arrow. During non-events, adult salmon are 
270 widely dispersed with no aggregations (b). The thermal plume, approximately $14{ }^{\circ} \mathrm{C}$, created by

271 the adjacent tributary entering the main river is shown in $(\mathrm{d})$.

272

\section{$273 \quad 3.2 \quad$ Hydraulic models}

274 The RF generated depth models were relatively robust for each event, with $A d j . R^{2}$ values ranging 275 from $0.79-0.82$ and RMSE between 0.26 and $0.28 \mathrm{~m}$ (see Table 2; Figure S2). Similarly, the 276 velocity and $\mathrm{Fr}$ models showed relatively high, and consistent, levels of accuracy with $\mathrm{Adj}$. $R^{2}=$ $2770.77-0.86\left(R M S E=0.04-0.05 \mathrm{~m} \cdot \mathrm{s}^{-1}\right)$, and Adj. $R^{2}=0.86(R M S E=0.01)$, respectively (see Table

278 2; Figure S3). For both apparent behavioural thermoregulation events, fish were located within or 279 close to the thermal plume, and avoided the thalweg, the section with the highest velocity and $F r$ 280 values (Figure 4a-c, and 4g-i). During optimal thermal regime conditions, fish were observed 281 opposite the plume, but still avoided the thalweg (Figure 4d-f).

284 Table 2 Optically derived bathymetric, and hydraulic model results for each event.

\begin{tabular}{cccc}
\hline $\begin{array}{c}\text { Hydraulic } \\
\text { parameter }\end{array}$ & $\begin{array}{c}\text { August behavioural } \\
\text { thermoregulation regime }\end{array}$ & $\begin{array}{c}\text { August optimal } \\
\text { thermal regime }\end{array}$ & $\begin{array}{c}\text { September behavioural } \\
\text { thermoregulation regime }\end{array}$ \\
\hline \multirow{2}{*}{ Depth $(\mathrm{m})$} & $A d j . R^{2}=0.82$ & $A d j . R^{2}=0.79$ & $A d j . R^{2}=0.81$ \\
& $\mathrm{RMSE}=0.26$ & $R M S E=0.28$ & $R M S E=0.26$ \\
$(N=952)$ & $(N=771)$ & $(N=952)$ \\
\hline \multirow{2}{*}{ Velocity } & $A d j . R^{2}=0.77$ & $A d j . R^{2}=0.81$ & $A d j . R^{2}=0.86$ \\
$(\mathrm{~m} \cdot \mathrm{s}-1)$ & $R M S E=0.05$ & $R M S E=0.05$ & $R M S E=0.04$ \\
& $(N=860)$ & $(N=744)$ & $(N=860)$ \\
\hline \multirow{3}{*}{ Froude } & $A d j . R^{2}=0.86$ & $A d j . R^{2}=0.85$ & $A d j . R^{2}=0.86$ \\
& $R M S E=0.01$ & $R M S E=0.01$ & $R M S E=0.01$ \\
& $(N=860)$ & $(N=744)$ & $(N=860)$ \\
\hline
\end{tabular}


August: Behavioural thermoregulation

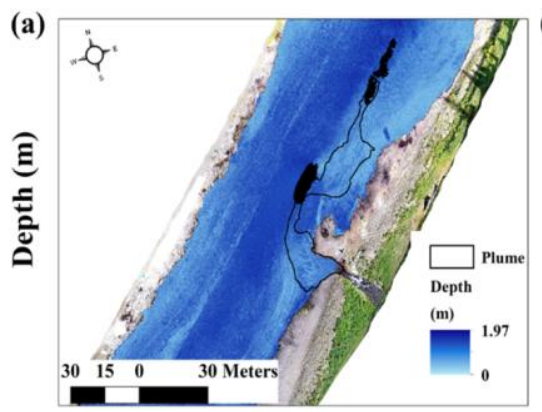

(b)

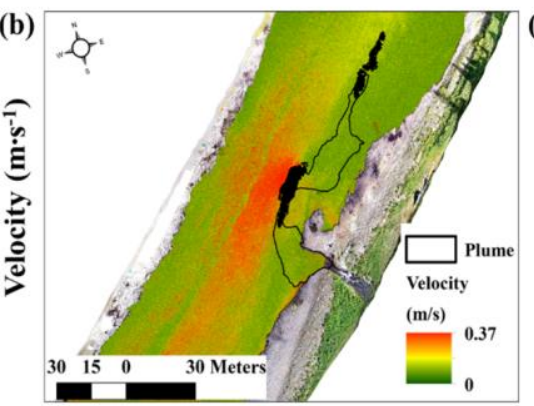

(c)

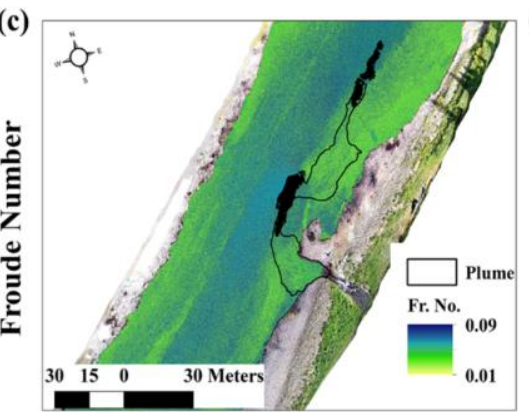

August: optimal temperature

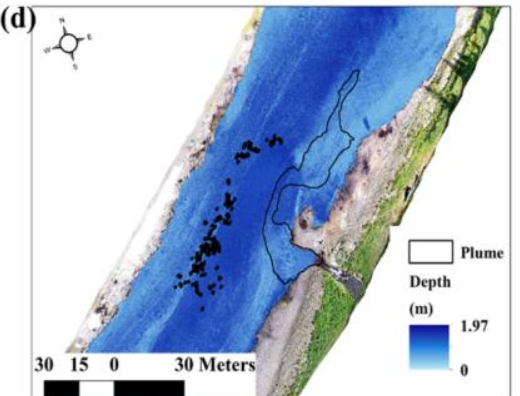

(e)
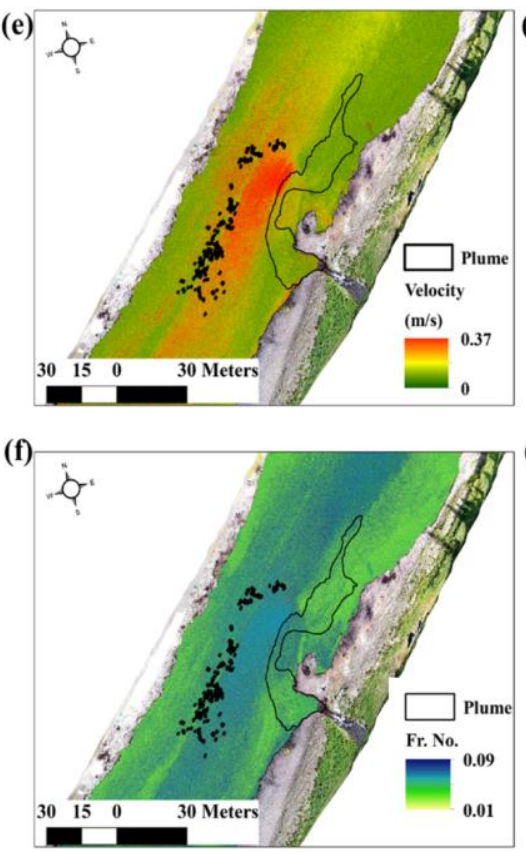

September: Behavioural thermoregulation

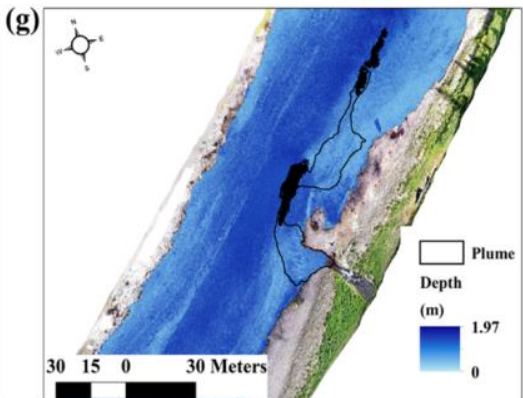

(h)

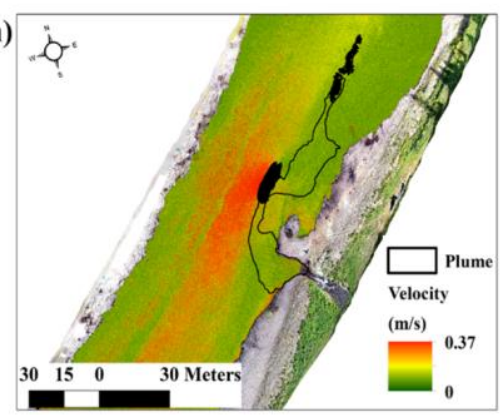

(i)

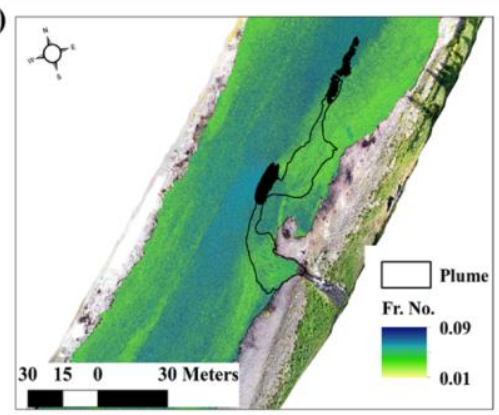

Figure 4 The position of adult Atlantic salmon (black features) during the apparent behavioural thermoregulation event in relation to the thermal plume (black polygon) on August 24 in relation to depth (a), velocity (b), and Froude number (c), and similarly for the optimal thermal conditions on August 28 (d, e, f), and the September 11 behavioural thermoregulation event (g, h, i).

\subsection{Hydraulic preference curves}

294 On the day of optimal thermal conditions (August 28) a total of $N=233$ fish, occupying $~ 14.8$

$295 \mathrm{~m}^{2}$, were identified in the image. On average each fish polygon for the optimal event had an areal 296 extent $=0.06 \mathrm{~m}^{2}$, encompassing $\sim 120$ pixels. Depth preferences for the optimal thermal condition 297 (August 28), were observed to be $\sim 1.3 \mathrm{~m}$, velocity preferences were $\sim 0.2 \mathrm{~m} \cdot \mathrm{s}^{-1}$, and $F r$ preferences 298 were $\sim 0.07$, while habitats located within $<1 \mathrm{~m}$ from boulders were noticeably preferred (Figure. 299 5). Distances $\sim 24 \mathrm{~m}$ from the thermal plume were preferred (Figure 5). 
The polygon that delimited the August 24 behavioural thermoregulation event was $\sim 74.4$ $\mathrm{m}^{2}$, and the areal extent of the September 11 behavioural thermoregulation event polygon was 68 $\mathrm{m}^{2}$ (see Figure 5). Preference indices for depth, velocity, $\mathrm{Fr}$, and distance to thermal plume were similar for both behavioural thermoregulation events, and markedly different from optimal thermal conditions (Figure 5). Depth preferences for the behavioural thermoregulations were observed to be $\sim 1.1 \mathrm{~m}$, velocity preferences were $\sim 0.16 \mathrm{~m} \cdot \mathrm{s}^{-1}$, and $F r$ preferences were $\sim 0.04$. Distances within $1 \mathrm{~m}$ of the thermal plume were preferred (Figure 5).
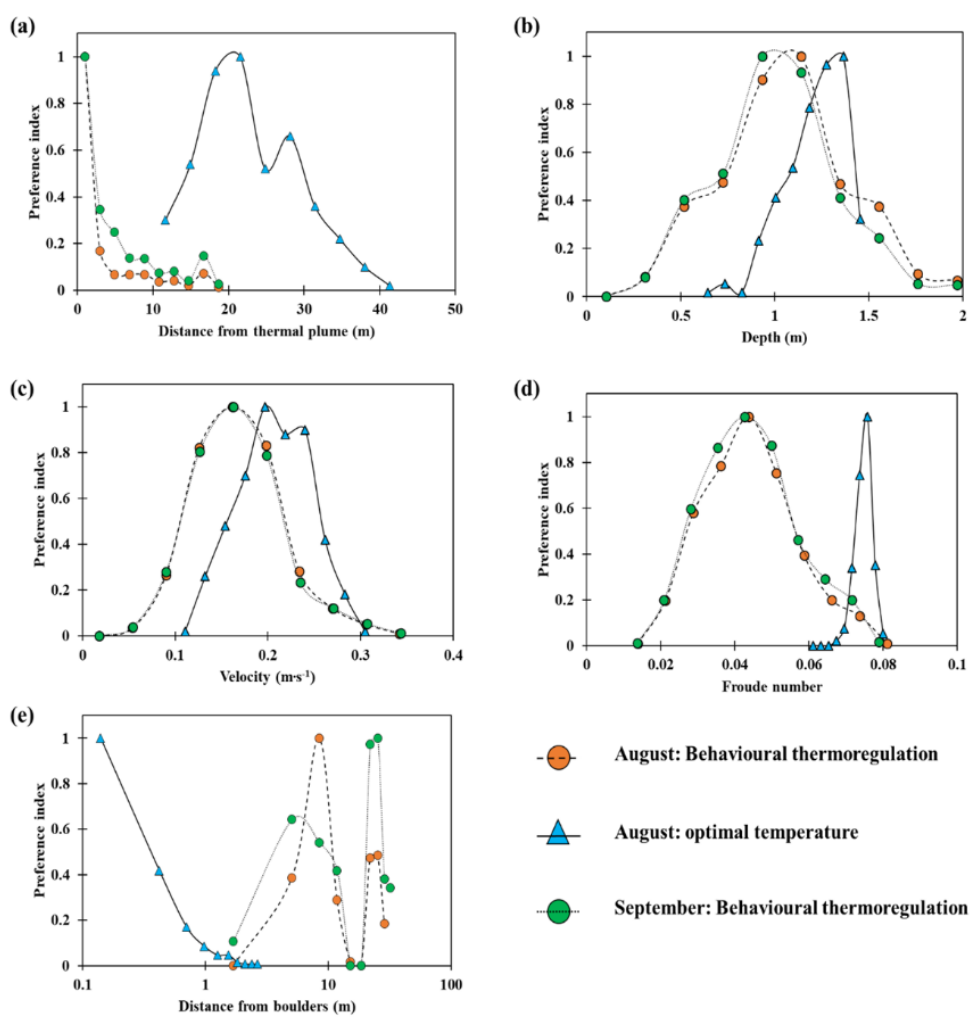

Figure 5 Habitat preference indices for optimal and behavioural thermoregulation conditions: distance from the thermal plume (a), depth (b), velocity (c), Froude number (d) and distance from boulders (e).

\section{Discussion}

\section{$313 \quad 4.1$ Summer thermo-hydraulic habitats of adult Atlantic salmon}

314 Using remotely sensed data for river temperature (TIR) and depth (RGB), we mapped a change in

315 summer habitat use for adult AS between optimal conditions and behavioural thermoregulation 
events. Our UAV images and ADCP data produced fine scale $(5 \mathrm{~cm})$ maps of adult locations, river thermo-hydraulics and in-stream features, i.e., boulders. From these data, we reveal that habitat preferences for optimal and behavioural thermoregulation events. The prior includes preferences for boulders, depth and velocity, while the latter details a preference for the coldwater plume and low $F r$ values.

Temperature preference for adult AS $16.5-17.5^{\circ} \mathrm{C}$ (Stehfest et al., 2017). Under stressful thermal conditions, they will move amongst mesohabitats in a river, which is attributed to behavioural thermoregulation (Dugdale et al., 2016; Wilbur et al., 2020). Our fine scale observations demonstrate that movements can capitalize on coldwater plumes created by, for example, inflowing tributaries (Otter brook, Little Southwest Miramichi - Corey et al., 2020). At our study location, the thermoregulation behaviour occurred when river temperatures outside the plume reached $19^{\circ} \mathrm{C}$. This is lower than behavioural thermaloreglation temperatures found by Shepard, (1995) in the Penobscot, Maine (USA), but is consistent with the findings of Frechette $e t$ al., (2018) in the Rivière Sainte-Marguerite Nord-Est, in Quebec, Canada. 
immediately downstream of the boulders in a region termed the "near-wake" region where flows reverse and move back upstream, and finally deceleration close to the bed downstream of the near wake region in a region termed the "far-wake" region (Papanicolaou et al., 2012). Papanicolaou et al. (2012) found that velocity modulations due to the presence of boulders were observed downstream, up to a length of 3.5 times the boulders diameter. We hypothesize that adult AS capitalize on the energy efficiencies provided by boulders, utilising both near- and far-wake regions during optimal thermal conditions (see Figure S3). The boulders likely provide hydraulic refuge where the recirculating upstream currents significantly reduce energetic costs (Jonsson et al., 2007). A proximity to boulders by adult AS is a well-understood characteristic among anglers. Interestingly, it was revealing to observe the adults moving away from boulders as river temperatures rose to physiologically stressful levels.

Adult AS also moved into shallower and lower velocity waters during the thermally stressful events (Figure 4 and 5). Our results suggest that these stressful events push adults away from generally preferred energetic conservation and predator protection locations, e.g., boulders and deep water locations, to access the cooler water. It was apparent that the best hydraulic indicators of preferred habitat during this thermoregulation behaviour were both velocity and $\mathrm{Fr}$ (Figure 4), which averaged $0.15 \mathrm{~m} . \mathrm{s}^{-1}$ and 0.04 , respectively, and were and clearly less than values during optimal thermal conditions. Low velocity and $F r$ values indicate sub-critical flow, thereby areas where less energy would be expended. This illustrates that thermal refuges for adult AS are defined by temperature, but may also be identified by depth and velocity characteristics, best represented by $F r$ number.

The high summer temperature events also pushed the AS into aggregations similar to the behaviour of juveniles during these events (Breau et al., 2007, Corey et al., 2020). The geometry created by aggregating adult AS displayed obclavate shapes (Figure 4 and 6a and b). The primary

371 driver is undoubtedly to provide access to the thermal plume (Frechette et al., 2020); however, the 372 geometry of the aggregation is similar to that utilised by cyclists to reduce aerodynamic-drag, a 373 formation known as a 'peloton'. Recent work by Blocken et al., (2018) found aerodynamic drag 374 was reduced by $90-95 \%$ in the mid-rear of the peloton when compared to an isolated cyclist. 375 This behaviour is also commonly used in schooling fishes to dampen hydraulic-drag (e.g., Weihs, 
376 1975; Daghooghi and Borazjani, 2015). We present a concept we term a 'thermal-peloton'. We

377 hypothesize that the observed thermal-peloton used by adult AS (Figure 6a) reduces thermal stress,

378 whilst also favourably modulates hydrodynamics. We predict that the geometry of the thermal

379 peloton attenuates hydraulic drag, thereby reducing energetic expenditure for the group, but with

380 potential costs for some individuals, e.g., the front of the peloton (see review by Trenchard and

381 Perc, 2016). Our observations are static, thus more studies will be required to establish if a salmon

382 peloton functions like the dynamic, human cyclist peloton where social interactions lead to

383 individuals moving among the high and low energy expenditure positions (Blocken et al., 2018). 

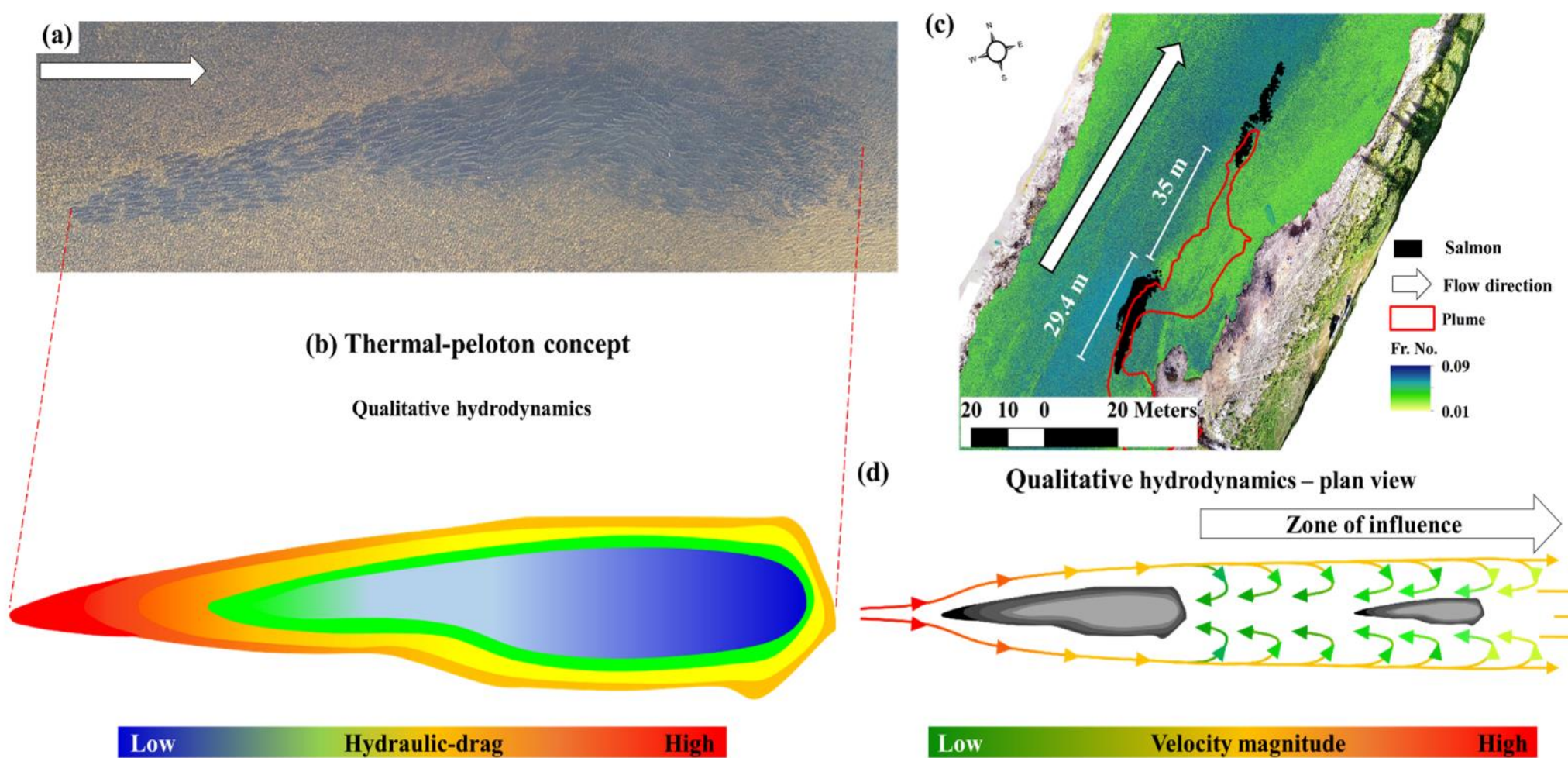

(d) Qualitative hydrodynamics - plan view

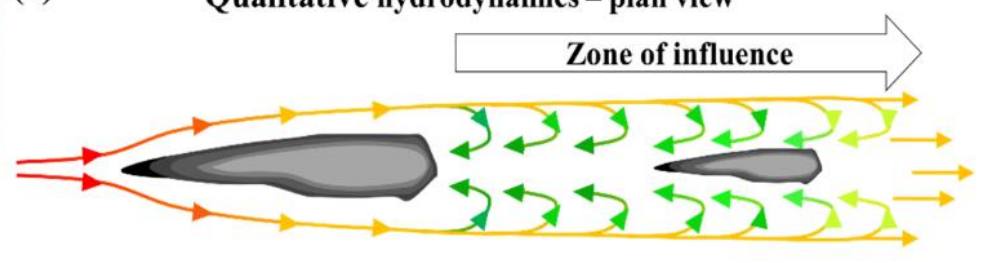

Low Velocity magnitude High

386 Figure 6 A behavioural thermoregulation event for adult Atlantic salmon and the concept of a 'thermal peloton" (see text). Two 387 aggregations of individuals existed; the upstream the upstream aggregation was larger (a) and (b) represents a schematic prediction of 388 the group's hydraulic drag. The two aggregations in relation to the thermal plume (c), and (d) represents a schematic prediction of the

389 velocity associate with the grou 
We observed two groups of adult AS during thermally stressfully conditions (Figure 4). The downstream group also appear to selected the deepest remaining area of the plume with lower Fr values $\sim 0.04$ (Figure 5 and $6 \mathrm{c}$ ). It is worth noting that TIR only measures the surface of the water, and mixing processes likely extend the plume beyond the observed surface extent (Handcock et al., 2012). The hydraulic conditions do however suggest hydrodynamic benefits to the downstream group due to the larger upstream group, which acts as a hydraulic structure that modulates hydraulic regimes around and behind the upstream group. Extrapolating the findings of Papanicolaou et al., (2012), the $~ 29$ m long upstream group could generate a zone of hydraulic influence that extends past the downstream group, i.e., assuming a zone of influence 3.5 time the length of the group (Figure 6d). As such, the upstream group most likely provides a bio-derived hydraulic refuge for the smaller downstream group.

\subsection{Utility of hyper-resolution sensors for ecological studies}

The fine-scale resolution of the thermal-hydraulics of the AS behaviour are extraordinary, but remotely sensed images and machine learning models are not without caveats. Passive depth mapping is underpinned by the physics of light attenuation in water (e.g., O'Sullivan et al., 2020), thus both colour and surface smoothness may interfere with interpretations. TIR temperatures only measure the surface of the water and in-river mixing processes likely shape the plume beyond the observed 2-dimensional, surface extent (e.g., Handcock et al., 2012); this may be why some individual AS appear "outside" the plume during the high temperature events (upper peloton). Our hydraulic variable maps were derived from a machine learning approach (Random Forest) and while emerging as a very powerful tools in the natural sciences, the approach has limitations, particularly machine learning models are poor extrapolators (e.g., Tyralis et al., 2019). The hydraulic conditions we report are consistent with our collective, years of experience on the Miramichi River (Burge, 2005); we and others will continue to explore the power and limitations of machine leaning models in river sciences (e.g., Tyralis et al., 2019; Zhu et al., 2020)

Remote sensing has revolutionized global and regional scale studies across myriad research fields, such as ecology (Torgersen et al., 1999), and geomorphology (Legleiter and Harrison, 2019). In this study, we illustrated how optical imagery acquired from a UAV can be used in concert with in-situ depth and velocity data to passively map adult AS and develop models of 
hydraulic habitats, and how paired thermal infrared imagery can be applied to detail thermal heterogeneity. These data provide an unrivaled viewpoint of behaviour and its link to hydraulic conditions, and consequently, open doors for rapid advances in river ecology and provides a blueprint for habitat restoration work. While current habitat restoration is mostly based on coarse scale interpretations of river hydraulics and engineering principles (see recent review by AdevaBustos et al., 2019), our findings indicate that the preferred habitat for adult AS during high temperature events is best described by fine-scale, $F r$. Adults also endure stress related to habitat restrictions during winter, and it is likely that the hydraulics under and around river ice used by AS will be best described by hydraulic variables such as $\mathrm{Fr}$ numbers that are already linked to other habitat choices, e.g., redd sites (Moir et al. 2002). We have demonstrated that such advances in ecology and hydraulic engineering using UAV-based sensors has the potential to instigate a paradigm shift for river sciences (Dugdale et al., 2019; Casa-mullet et al., 2020). The age of applying hyper-resolution, remote sensing for river science and aquatic ecology is immensely exciting.

\section{References}

Adeva-Bustos, A., Alfredsen, K., Fjeldstad, H.-P., \& Ottosson, K. (2019). Ecohydraulic Modelling to Support Fish Habitat Restoration Measures. Sustainability, 11(5), 1500. https://doi.org/10.3390/su11051500

Andrews, S. N., O’Sullivan, A. M., Helminen, J., Arluison, D. F., Samways, K. M., Linnansaari, T., \& Curry, R. A. (2020). Development of active numerating side-scan for a high-density overwintering location for endemic shortnose sturgeon (Acipenser brevirostrum) in the Saint John River, New Brunswick. Diversity, 12(1). https://doi.org/10.3390/d12010023

Blocken, B., van Druenen, T., Toparlar, Y., Malizia, F., Mannion, P., Andrianne, T., ... Diepens, J. (2018). Aerodynamic drag in cycling pelotons: New insights by CFD simulation and wind tunnel testing. Journal of Wind Engineering and Industrial Aerodynamics, 179, 319337. https://doi.org/10.1016/j.jweia.2018.06.011

Breau, C., Cunjak, R. A., \& Bremset, G. (2007). Age-specific aggregation of wild juvenile Atlantic salmon Salmo salar at cool water sources during high temperature events. Journal of Fish Biology, 71(4), 1179-1191. https://doi.org/10.1111/j.1095-8649.2007.01591.x

Breau, Cindy, Cunjak, R. A., \& Peake, S. J. (2011). Behaviour during elevated water temperatures: can physiology explain movement of juvenile Atlantic salmon to cool water? Journal of Animal Ecology, 80(4), 844-853. https://doi.org/10.1111/j.13652656.2011.01828.x 
Burge, L. M. (2005). Wandering Miramichi rivers, New Brunswick, Canada. Geomorphology, 69(1-4), 253-274. https://doi.org/10.1016/j.geomorph.2005.01.010

Caissie, D., Satish, M. G., \& El-Jabi, N. (2007). Predicting water temperatures using a deterministic model: Application on Miramichi River catchments (New Brunswick, Canada). Journal of Hydrology, 336(3-4), 303-315.

https://doi.org/10.1016/j.jhydrol.2007.01.008

Casas-Mulet, R., Pander, J., Ryu, D., Stewardson, M. J., \& Geist, J. (2020). Unmanned Aerial Vehicle (UAV)-Based Thermal Infra-Red (TIR) and Optical Imagery Reveals Multi-Spatial Scale Controls of Cold-Water Areas Over a Groundwater-Dominated Riverscape. Frontiers in Environmental Science, 8, 64. https://doi.org/10.3389/fenvs.2020.00064

Corey, E., Linnansaari, T., Dugdale, S. J., Bergeron, N., Gendron, J., Lapointe, M., \& Cunjak, R. A. (2020). Comparing the behavioural thermoregulation response to heat stress by Atlantic salmon parr ( Salmo salar ) in two rivers. Ecology of Freshwater Fish, eff.12487. https://doi.org/10.1111/eff.12487

Crisp, D. T. (1996). Environmental requirements of common riverine European salmonid fish species in fresh water with particular reference to physical and chemical aspects. Hydrobiologia. Kluwer Academic Publishers. https://doi.org/10.1007/BF00007847

Daghooghi, M., \& Borazjani, I. (2015). The hydrodynamic advantages of synchronized swimming in a rectangular pattern. Bioinspiration and Biomimetics, 10(5), 56018. https://doi.org/10.1088/1748-3190/10/5/056018

DFO. 2012. Temperature threshold to define management strategies for Atlantic salmon (Salmo salar) fisheries under environmentally stressful conditions. DFO Can. Sci. Advis. Sec. Sci. Advis. Rep. 2012/019.

Dugdale, S. J., Franssen, J., Corey, E., Bergeron, N. E., Lapointe, M., \& Cunjak, R. A. (2016). Main stem movement of Atlantic salmon parr in response to high river temperature. Ecology of Freshwater Fish, 25(3), 429-445. https://doi.org/10.1111/eff.12224

Dugdale, S. J., Kelleher, C. A., Malcolm, I. A., Caldwell, S., \& Hannah, D. M. (2019). Assessing the potential of drone-based thermal infrared imagery for quantifying river temperature heterogeneity. Hydrological Processes, 33(7), 1152-1163. https://doi.org/10.1002/hyp.13395

Ebersole, J. L., Liss, W. J., \& Frissell, C. A. (2003). Cold water patches in warm streams: physiochemical characteristics and the influence of shading. Journal of the American Water Resources Association, 39(2), 355-368. https://doi.org/10.1111/j.17521688.2003.tb04390.x

Erkinaro, J., Okland, F., Moen, K., Niemela, E., \& Rahiala, M. (1999). Return migration of Atlantic salmon in the River Tana: the role of environmental factors. Journal of Fish Biology, 55(3), 506-516. https://doi.org/10.1111/j.1095-8649.1999.tb00695.x

Esri: GIS Mapping Software, Spatial Data Analytics and Location Platform. (2020) 
Frechette, D. M., Dugdale, S. J., Dodson, J. J., \& Bergeron, N. E. (2018). Understanding summertime thermal refuge use by adult Atlantic salmon using remote sensing, river temperature monitoring, and acoustic telemetry. Canadian Journal of Fisheries and Aquatic Sciences, 75(11), 1999-2010. https://doi.org/10.1139/cjfas-2017-0422

Frechette, D. M., Dionne, M., Dodson, J. J., \& Bergeron, N. E. (2020). Atlantic salmon movement patterns and habitat use during colonization of novel habitat. Transactions of the American Fisheries Society, tafs.10284. https://doi.org/10.1002/tafs.10284

Gibson, R.J., 1993. The Atlantic salmon in fresh water: spawning, rearing and production. Reviews in fish biology and fisheries, 3(1), pp.39-73.

Guerrero, M., \& Lamberti, A. (2011). Flow Field and Morphology Mapping Using ADCP and Multibeam Techniques: Survey in the Po River. Journal of Hydraulic Engineering, 137(12), 1576-1587. https://doi.org/10.1061/(ASCE)HY.1943-7900.0000464

Handcock, R. N., Torgersen, C. E., Cherkauer, K. a., Gillespie, A. R., Tockner, K., Faux, R. N., \& Tan, J. (2012). Thermal Infrared Remote Sensing of Water Temperature in Riverine Landscapes. Fluvial Remote Sensing for Science and Management, 85-113. https://doi.org/10.1002/9781119940791.ch5

Heggenes, J. (1996). Habitat selection by brown trout (Salmo trutta) and young Altantic salmon ( $S$. salar) in streams: static and dyanmics hydraulic modelling. Regulated Rivers: Research \& Management, 12(2-3), 155-169. https://doi.org/10.1002/(SICI)10991646(199603)12:2/3<155::AID-RRR387>3.0.CO;2-D

Heggenes, J., Brabrand, Åg., \& Saltveit, S. (1990). Comparison of Three Methods for Studies of Stream Habitat Use by Young Brown Trout and Atlantic Salmon. Transactions of the American Fisheries Society, 119(1), 101-111. https://doi.org/10.1577/15488659(1990)119<0101:COTMFS>2.3.CO;2

Jonsson, B., Jonsson, N., \& Hansen, L. P. (2007). Factors affecting river entry of adult Atlantic salmon in a small river. Journal of Fish Biology, 71(4), 943-956. https://doi.org/10.1111/j.1095-8649.2007.01555.x

Jordan, D. C., \& Fonstad, M. A. (2005). Two dimensional mapping of River Bathymetry and power using aerial photography and GIS on the Brazos river, Texas. Geocarto International, 20(3), 13-20. https://doi.org/10.1080/10106040508542351

Keenleyside, M. H. A. (1962). Skin-diving Observations of Atlantic Salmon and Brook Trout in the Miramichi River, New Brunswick. Journal of the Fisheries Research Board of Canada, 19(4), 625-634. https://doi.org/10.1139/f62-042

Kurylyk, B. L., MacQuarrie, K. T. B., Linnansaari, T., Cunjak, R. A., \& Curry, R. A. (2015). Preserving, augmenting, and creating cold-water thermal refugia in rivers: concepts derived from research on the Miramichi River, New Brunswick (Canada). Ecohydrology, 8(6), 1095-1108. https://doi.org/10.1002/eco.1566

Lane, S. N., Gentile, A., \& Goldenschue, L. (2020). Combining UAV-Based SfM-MVS Photogrammetry with Conventional Monitoring to Set Environmental Flows: Modifying Dam Flushing Flows to Improve Alpine Stream Habitat. Remote Sensing, 12(23), 3868. 
https://doi.org/10.3390/rs12233868

Legleiter, C. J., \& Harrison, L. R. (2019). Remote Sensing of River Bathymetry: Evaluating a Range of Sensors, Platforms, and Algorithms on the Upper Sacramento River, California, USA. Water Resources Research, 55(3), 2142-2169. https://doi.org/10.1029/2018WR023586

Lennox, R. J., Eliason, E. J., Havn, T. B., Johansen, M. R., Thorstad, E. B., Cooke, S. J., ... Uglem, I. (2018). Bioenergetic consequences of warming rivers to adult Atlantic salmon Salmo salar during their spawning migration. Freshwater Biology, 63(11), 1381-1393. https://doi.org/10.1111/fwb.13166

Linnansaari, T., \& Cunjak, R. A. (2013). Effects of ice on behaviour of juvenile Atlantic salmon ( Salmo salar ). Canadian Journal of Fisheries and Aquatic Sciences, 70(10), 1488-1497. https://doi.org/10.1139/cjfas-2012-0236

Lyzenga, D. R. (1981). Remote sensing of bottom reflectance and water attenuation parameters in shallow water using aircraft and landsat data. International Journal of Remote Sensing, 2(1), 71-82. https://doi.org/10.1080/01431168108948342

Malcolm, I.A., Greig, S., Youngson, A.F. and Soulsby, C. (2008) Hyporheic influences on salmon embryo survival and performance. In Sear, D.A. and DeVries, P. (Eds) Salmonid Spawning Habitat in Rivers: Physical Controls, Biological Responses, and Approaches to Remediation, Symposium 65, 376pp

Marcus, W. A., \& Fonstad, M. A. (2010). Remote sensing of rivers: the emergence of a subdiscipline in the river sciences. Earth Surface Processes and Landforms, 35(15), 18671872. https://doi.org/10.1002/esp.2094

Mocq, J., St-Hilaire, A., \& Cunjak, R. A. (2018). Do habitat measurements in the vicinity of Atlantic salmon ( Salmo salar ) parr matter? Fisheries Management and Ecology, 25(1), 22-30. https://doi.org/10.1111/fme.12262

Moir, H. ., Soulsby, C., \& Youngson, A. . (2002). Hydraulic and sedimentary controls on the availability and use of Atlantic salmon (Salmo salar) spawning habitat in the River Dee system, north-east Scotland. Geomorphology, 45(3-4), 291-308. https://doi.org/10.1016/S0169-555X(01)00160-X

Morash, A. J., Speers-Roesch, B., Andrew, S., \& Currie, S. (2021). The physiological ups and downs of thermal variability in temperate freshwater ecosystems. Journal of Fish Biology, jfb.14655. https://doi.org/10.1111/jfb.14655

O’Sullivan, A. M., Devito, K. J., Ogilvie, J., Linnansaari, T., Pronk, T., Allard, S., \& Curry, R. A. (2020). Effects of topographic resolution and geologic setting on spatial statistical river temperature models. Water Resources Research. https://doi.org/10.1029/2020wr028122

O’Sullivan, A. M., Wegscheider, B., Helminen, J., Cormier, J. G., Linnansaari, T., Wilson, D. A., \& Curry, R. A. (2020). Catchment-scale, high-resolution, hydraulic models and habitat maps - a salmonid's perspective. Journal of Ecohydraulics, 1-16. https://doi.org/10.1080/24705357.2020.1768600

Ouellet, V., St-Hilaire, A., Dugdale, S. J., Hannah, D. M., Krause, S., \& Proulx-Ouellet, S. 
(2020, September 20). River temperature research and practice: Recent challenges and emerging opportunities for managing thermal habitat conditions in stream ecosystems. Science of the Total Environment. Elsevier B.V. https://doi.org/10.1016/j.scitotenv.2020.139679

Papanicolaou, A. N., Kramer, C. M., Tsakiris, A. G., Stoesser, T., Bomminayuni, S., \& Chen, Z. (2012). Effects of a fully submerged boulder within a boulder array on the mean and turbulent flow fields: Implications to bedload transport. Acta Geophysica, 60(6), 15021546. https://doi.org/10.2478/s11600-012-0044-6

Reynolds, W. W., \& Casterlin, M. E. (1979). Behavioral thermoregulation and the "final preferendum" paradigm. Integrative and Comparative Biology, 19(1), 211-224. https://doi.org/10.1093/icb/19.1.211

Ritter, T. D., Zale, A. V., Grisak, G., \& Lance, M. J. (2020). Groundwater Upwelling Regulates Thermal Hydrodynamics and Salmonid Movements during High-Temperature Events at a Montane Tributary Confluence. Transactions of the American Fisheries Society, 149(5), 600-619. https://doi.org/10.1002/tafs.10259

Sagawa, T., Yamashita, Y., Okumura, T., \& Yamanokuchi, T. (2019). Satellite Derived Bathymetry Using Machine Learning and Multi-Temporal Satellite Images. Remote Sensing, 11(10), 1155. https://doi.org/10.3390/rs11101155

Shepard, S. L. (1995). Atlantic salmon spawning migrations in the Penobscot River, Maine: fishways, flows and high temperatures. MSc Thesis. University of Massachusetts

Stehfest, K. M., Carter, C. G., McAllister, J. D., Ross, J. D., \& Semmens, J. M. (2017). Response of Atlantic salmon Salmo salar to temperature and dissolved oxygen extremes established using animal-borne environmental sensors. Scientific Reports, 7(1). https://doi.org/10.1038/s41598-017-04806-2

Torgersen, C. E., Price, D. M., Li, H. W., \& McIntosh, B. A. (1999). Multiscale thermal refugia and stream habitat associations of chinook salmon in northeastern Oregon. Ecological Applications, 9(1), 301-319. https://doi.org/10.1890/10510761(1999)009[0301:MTRASH]2.0.CO;2

Trenchard, H., \& Perc, M. (2016, September 1). Energy saving mechanisms, collective behavior and the variation range hypothesis in biological systems: A review. BioSystems. Elsevier Ireland Ltd. https://doi.org/10.1016/j.biosystems.2016.05.010

Tyralis, H., Papacharalampous, G., \& Langousis, A. (2019). A Brief Review of Random Forests for Water Scientists and Practitioners and Their Recent History in Water Resources. Water, 11(5), 910. https://doi.org/10.3390/w11050910

Webb, J.E.N.A.P.E., Verspoor, E., Aubin-Horth, N., Romakkaniemi, A. and Amiro, P., 2007. The Atlantic salmon. The Atlantic salmon: genetics, conservation and management, pp.1756.

Weihs, D. (1975). Some Hydrodynamical Aspects of Fish Schooling. In Swimming and Flying in Nature (pp. 703-718). Springer US. https://doi.org/10.1007/978-1-4757-1326-8_16

Wilbur, N. M., O’Sullivan, A. M., MacQuarrie, K. T. B., Linnansaari, T., \& Curry, R. A. (2020). 
Characterizing physical habitat preferences and thermal refuge occupancy of brook trout (Salvelinus fontinalis) and Atlantic salmon (Salmo salar) at high river temperatures. River Research and Applications, 36(5). https://doi.org/10.1002/rra.3570

Zhu, S., \& Piotrowski, A. P. (2020). River/stream water temperature forecasting using artificial intelligence models: a systematic review. Acta Geophysica. Springer Science and Business Media Deutschland GmbH. https://doi.org/10.1007/s11600-020-00480-7

\section{Data availability statement}

The data in this study detail a critical thermal refuge that could be easily exploited if its location was revealed. The data generated within are georeferenced. In the interest of conservation, the data are being held by the lead author. Any queries regarding these data can be addressed to the lead author. 